\title{
Les virus arrivent en force sur la scène de I'immunopathologie et des cancers humains
}

Il y a encore quelques années la responsabilité des virus dans les affections humaines n'était clairement assurée que dans les maladies infectieuses aiguës. Puis vinrent les associations rapportées entre les infections à virus d'EpsteinBarr, à virus herpès, à virus hépatitique, à virus du papillome... et des cancers variés. Enfin, plus récemment, furent décrit les rétrovirus oncogènes humains HTLV 1 et 2 et l'HIV (ou $L A V-H T L V 3)$ agent responsable du SIDA... et cela n'est manifestement pas fini.

Salahuddin et al, $d u$ laboratoire de Robert Gallo, viennent de décrire un nouveau virus à $A D N$ double brin de la famille herpès (génome de taille supérieure à 110 kilobases) capable de se répliquer, in vitro, dans les lymphocytes $B[1,2]$. Ce nouvel agent, appelé
HBLV (human B-lymhotropic virus), a été isolé à partir de tumeurs (lymphomes et syndromes lymphoprolifératifs) détectées chez six malades dont deux étaient également positifs pour HIV. Tout en restant prudent sur la responsabilité d'HBLV dans les lymphomes, la découverte doit de toutes façons être considérée comme importante.

Un autre agent viral, rétroviral celui$l \dot{a}$, pourrait être l'agent infectieux responsable de la maladie de Kawasaki, une vascularite aiguë sévère de l'enfance et de l'adolescence, associée dà des perturbations des cellules $T$ (activation de la population $T_{-} C D 4+$, helper, et diminution de la population $T_{-}$ $C D 8+$, suppressive).

On retrouve en effet, dans la fraction particulaire d'un surnageant de culture de cellules mononucléés circulantes des malades, une activité enzymatique de transcriptase reverse de type rétro-virale, activité qui peut être "transférée "à une lignée en culture de cellules T. SIDA, cancers, maladies auto-immunes et infections aiguës... voilà bien des raisons vraiment de considérer comme prioritaires les recherches en virologie et pharmocologie anti-virale!

A. $\mathbf{K}$.

1. Salahuddin SZ, Ablashi DV, Markham PD, et al. Isolation or a new virus, $\mathrm{HBLV}$, in patients with lymphoproliferative disorders. Science 1986 ; 234 : 596-601.

2. Josephs SF, Salahuddin SZ, Ablashi DV, Schachter F, Woong-Staal F, Gallo R. Genomic analysis of the human B-lymphotropic virus (HBLV). Science 1986; 234 : 601-3. 3. Burns JC, Geha RS, Schneeberger EE, et al. Polymerase activity in lymphocyte culture supernatants from patients with Kawasaki disease. Nature 1986 ; 323 : 814-6.
Lu Léficit en triose phosphate isomérase est une des anomalies les plus rares, mais sans doute la plus sévère de toutes celles des enzymes de la glycolyse. Dans tous les cas étudiés, il existe une activité résiduelle et la thermostabilité est diminuée. L'ADN de deux sujets atteints non apparentés a été analysé : dans les deux cas la mutation était la même, aboutissant au remplacement d'un acide glutamique en position 104 (sur 248 acides aminés) par un acide aspartique. Un changement aussi minime, sans modification de charge, suffit à bouleverser la structure de la protéine au point de la rendre thermolabile in vitro et instable in vivo.

Daar IO, et al. Proc Natl Acad Sci USA 1986 ; 83 : 7903-7.
LE CGRP (calcitonin gene-related peptide) est un produit de l'excision-épissage alternatif du transcrit primitif du gène de la calcitonine dans les tissus nerveux $\left(m / s n^{\circ} 8\right.$, vol. 1 , p. 442). Il est capable d'augmenter la synthèse de récepteurs de l'acétylcholine dans des myotubes en culture. Présent à l'extrémité des motoneurones au moment de la formation de la jonction neuromusculaire, le CGRP pourrait donc constituer un facteur trophique libéré par les extrémités nerveuses et provoquant une augmentation locale de la synthèse de récepteurs de l'acétylcholine indispensable à la formation des plaques motrices.

New HV, Mudge AW. Nature $1986 ; 323$ : 809-11.
Le lathyrisme est une affection fréquente dans certaines parties d'Asie et d'Afrique, liée à la consommation d'une plante : le Lathyrus sativus, ou " gesse chiche ". Il se caractérise par des troubles moteurs à symptomatologie pyramidale. Ces symptômes ont pu être reproduits chez des macaques par l'ingestion soit de graines ou d'extraits de graines de Lathyrus, soit d'un dérivé d'acide aminé contenu dans la gesse, le bêta-Noxalylamino-L-alanine (BOAA), un puissant agoniste du glutamate, neurotransmetteur excitateur. On a ainsi un exemple supplémentaire d'un agent toxique capable de provoquer chez l'homme une maladie neurologique.

Spencer PS, et al. Lancet 1986 ; ii : 1066-7. 